\title{
Interface shear and pressure characteristics of wheelchair seat cushions
}

\author{
Jonathan S. Akins; ${ }^{*}$ Patricia E. Karg, MS; ${ }^{2}$ David M. Brienza, PhD ${ }^{1-2}$ \\ ${ }^{1}$ Department of Bioengineering, Swanson School of Engineering, University of Pittsburgh, Pittsburgh, PA; \\ ${ }^{2}$ Department of Rehabilitation Sciences and Technology, School of Health and Rehabilitation Sciences, University of \\ Pittsburgh, Pittsburgh, PA
}

\begin{abstract}
Pressure ulcer incidence rates have remained con stant despite advances in sup port surface technology. Interface shear stress is recognized as a risk factor for pressure ulcer development and is the focus of many shear reduction technologies incorporated into wheelchair cushions; however, shear reduction has not been quantified in the literature. We evaluated $21 \mathrm{com}$ mercial wheelchair seat cushio ns using a new methodology developed to quantify inte rface shear stress, interface pressure, and horizontal stiffness. Interface shear stress increased signifi cantly with applied horizonta 1 indenter displacement, while no significant difference was found for interface pressure. Material of construction resulted in signific ant differences in inte rface shear stress, interface pressure, and horizontal stiffness. This study shows that the existing International Organization for Standardization (ISO) 16840-2 horizontal stiffness measure provides similar information to the new horizontal stiffness measure. The lack of a relationship between interface shear stress and the overall horizontal stiffness measure, however, suggests that a pressure and shear force sensor should be used with the ISO 16840-2 horizontal stiffness measure to fully quantify a cushion's ability to reduce interface shear stress at the patient's bony prominences.
\end{abstract}

Key words: decubitus ulcer, interface, pressure, pressure sore, pressure ulcer, shear force, shear stress, stiffness, support surface, wheelchair seat cushion.

\section{INTRODUCTION}

In the United States, annual pressure ulcer treatment costs have risen from $\$ 1.34$ billion in 1992 [1] to approximately $\$ 17.2$ billion in 2003 [2], with nearly 90 percent billed to Medicare or Medicaid. In 2003, approximately 455,000 hospital stays were caused principally by pressure ulcers and 167,000 hospital stays were for paralysis and/or spinal cord injury (SCI) [2]. The average hospital charge per stay was $\$ 37,800$, resulting in $\$ 6.3$ billion in treatment costs for the SCI population. With constant incidence rates of approximately 7.6 percent from 1999 to 2004 [3], pressure ulcer prevention is essential.

Wheelchair seat cushions are designed to provide comfort and aid against pressure ulcer development [4]. To aid against pressure ulcers, cushions are designed to re duce extrinsic risk factors known to increase the risk of pressure ulcers. The mechanical extrinsic risk factors are pressure and shear [5]. Literature is available on the interface pressure and pressure redistribution characteristics of commercial cushions [6-7]; however, no study has evaluated interface shear stress of commercial cushions. Animal and human studies have demo nstrated that shear forces

\footnotetext{
Abbreviations: HCPCS $=$ Healthcare Common Procedure Coding System, ICC = intraclass correlation coefficient, ISO = International Organization for Standardization, IT = ischial tuberosity, NIDRR $=$ National Institute on Disability and Reh abilitation Research, $\mathrm{RCLI}=$ rigid cushion loading indenter, $\mathrm{SCI}=$ spinal cord injury, $\mathrm{TTC}=$ The $\mathrm{T}$ echnology Collaborative, $\mathrm{VE}=$ viscoelastic.

*Address all correspondence to Jonathan S. Akins, MS; Department of Bioengineering, 3830 S. Water St, Pittsburgh, PA 15203; 412-246-0460; fax: 412-246-0461.

Email: jsa14@pitt.edu

DOI:10.1682/JRRD.2009.09.0145
} 
compromise tissue integrity. The animal studies identified that shear forces applied to bony prominences increased the severity of pressure ulcers compared with pressure alone [8-9], a nd the human studies ide ntified that shear forces decreased cutaneous blood flow [10-13]. The literature has established the importance of reduc ing shear; yet no previous study has evalua ted interface shear stress of commercial cushions. Information on this cushion characteristic may aid clinicians in selecting the appropriate cushion to me et their patients' needs and benefit cushion designers with a technique to quantify shear reduction. The International Organization for Standardization (ISO) published a standardized method for measuring the horizontal stiffness of seat cushions. The rationale for the IS O standard is that the degree of horizontal stiffness a cushion has relates to the amount of shear stress imparted by the cushion to the pat ient's soft tissue [14]. The purpose of this study was to quantify interface shear stress, interface pressure, and horizontal stiffness for commercial wheelchair seat cushions and de termine whether a relationship exists between interface shear stress and horizontal stiffness of cushions.

\section{METHODS}

\section{Cushions}

Twenty-one cushions representing all Healthcare Common Procedure Coding System (HCPCS) categories, except custom-fabricated seat cushions (E2609), were evaluated in this study (Table 1). Categories included general use (E2601), adjustable/nonadjustable skin protection (K0734/ E2603), positioning (E2605), and adjustable/nonadjustable combination skin protection and positioning cushions

Table 1.

Wheelchair seat cushions listed by Healthcare Common Procedure Coding System (HCPCS) category.

\begin{tabular}{|c|c|c|c|c|c|}
\hline $\begin{array}{l}\text { HCPCS } \\
\text { Code }\end{array}$ & Product Name & Cushion Cover & Manufacturer & $\begin{array}{l}\text { Model } \\
\text { Number }\end{array}$ & Material(s) of Construction \\
\hline \multirow[t]{4}{*}{$\overline{\mathrm{E} 2601}$} & MOSAIC & Standard two-way stretch & $\mathrm{ROHO}^{*}$ & MOS1616C & Segmented air cell \\
\hline & Jay Basic & Incontinence resistant & Sunrise Medical ${ }^{\dagger}$ & 305-MJ & Contoured elastic foam \\
\hline & Curve & Comfort-Tek & Comfort Company & 463G-1616-B & Contoured elastic foam \\
\hline & Stimulite Silver & Polyester & Supracor ${ }^{\S}$ & SI1616 & Honeycomb \\
\hline \multirow[t]{3}{*}{ K0734 } & $\begin{array}{l}\text { HIGH PROFILE } \\
\text { Single Compartment }\end{array}$ & Standard two-way stretch & $\mathrm{ROHO}$ & IR99C & Segmented air cell \\
\hline & Adjuster & Comfort-Tek & Comfort Company & AJ-F-1616 & Independent air cell \\
\hline & Jay J2 Deep Contour & Ballistic stretch & Sunrise Medical & 2466 & Viscous fluid/contoured elastic foam \\
\hline \multirow[t]{3}{*}{$\overline{\mathrm{E} 2603}$} & TRIUMPH & Standard two-way stretch & ROHO & TS1616C & Viscoelastic foam \\
\hline & Ascent & Comfort-Tek & Comfort Company & HY-GF-1616 & Contoured elastic foam \\
\hline & Jay Xtreme & LoShear & Sunrise Medical & 966LS & Viscous fluid/contoured elastic foam \\
\hline E2605 & Jay Soft Combi P & Incontinence resistant & Sunrise Medical & B2205 $(15.5 \times 16)$ & Contoured elastic foam \\
\hline \multirow[t]{3}{*}{ K0736 } & $\begin{array}{l}\text { HIGH PROFILE } \\
\text { QUADTRO SELECT }\end{array}$ & Standard two-way stretch & $\mathrm{ROHO}$ & QS99C & Segmented air cell \\
\hline & Vector & Comfort-Tek & Comfort Company & VT-F-1616 & Independent air cell \\
\hline & Jay J2 Deep Contour P & Ballistic stretch & Sunrise Medical & $2466 \mathrm{P}$ & Viscous fluid/contoured elastic foam \\
\hline \multirow[t]{4}{*}{$\bar{E} 2607$} & Harmony & Standard two-way stretch & $\mathrm{ROHO}$ & $\mathrm{H} 1616 \mathrm{C}$ & Segmented air cell \\
\hline & $\operatorname{Maxx}$ & Comfort-Tek & Comfort Company & MAXFF-1616 & Gel and elastic foam \\
\hline & Jay Easy & Incontinence resistant & Sunrise Medical & JE1616C & Viscous fluid/contoured elastic foam \\
\hline & Stimulite Contoured & Polyester & Supracor & CD1616 & Honeycomb \\
\hline \multicolumn{6}{|c|}{$\begin{array}{l}\text { The ROHO Group, Inc; Belleville, Illinois. } \\
\text { †Sunrise Medical, Inc; Longmont, Colorado. } \\
{ }^{\dagger} \text { The Comfort Company; Bozeman, Montana. } \\
{ }_{\text {§Supracor, Inc; San Jose, California. }}\end{array}$} \\
\hline
\end{tabular}


(K0736/E2607) [15]. Cushions were chosen from manufacturers with a large market share. The ROHO Group, Inc, (Belleville, Illinois); Sunrise Medical, Inc, (Longmont, Colorado); and The Comfort Company (Bozeman, Montana) each have at least one cushion in each HCPCS category, and Supracor, Inc, (San Jose, California) has at least one cushion in each nonadjustable ca tegory. Supracor was chosen specifically because it does not of fer adjustable cushions. A shear-reducing cushion cover was c hosen for each cushion when available.

\section{Instrumentation}

Shear and pressure characteristics of the cushions were obtained using a test apparatus (Figure 1) that consisted of a (1) Material Test System (MTS Systems Corp; Eden Prairie, Minnesota); (2) load cell (MTS Systems Corp); (3) loading rig; (4) ri gid cushion loading indenter (RCLI); (5) digital indicator (Swiss Precision Instruments, Inc; Garden Grove, California); and (6) pressure and shear force sensor (Pr edia, Molten Corp; Hiroshima, Japan). The loading rig was capable of applying a vertical load of up to $830 \mathrm{~N}( \pm 10 \mathrm{~N})$ to the cushions via the RCLI, measuring vertical and horizontal displacements $( \pm 1 \mathrm{~mm})$ of the RCLI, and supporting a wheelchair seat cushion on a rigid horizontal surface without flexing. The RCLI was manufactured from fiberglass with dimensions as specified in "Annex A" of ISO 16840-2 [14]. Interface pressure and interface shear force were measured from the pressure and shear force sensor $(10 \mathrm{~Hz})$, and horizontal force was measured with the load cell $(10 \mathrm{~Hz})$. The pressure and shear force sensor (sensor) was adhered just anterior to the left isch ial tuberosity (IT) of the RCLI with double-sided tape. The location provided a flat, rigid surface to avoid bending of the sensor.

The sensor measured pressure with air displacement and shear force with a strain gauge. The sensor is made of flexible plastic and is elliptical in shape (Figure 2). The sensor has an analog output for data collection and internal memory for storing up to five pressure and shear measurements. The sensor measured pressure ranging from 0 to $200 \mathrm{mmHg}$ and shear force ranging from 0 to 50 $\mathrm{N}$. Interface shear stress was calculated by dividing interface shear force by the shear-sensing area $\left(28.14 \mathrm{~cm}^{2}\right)$.

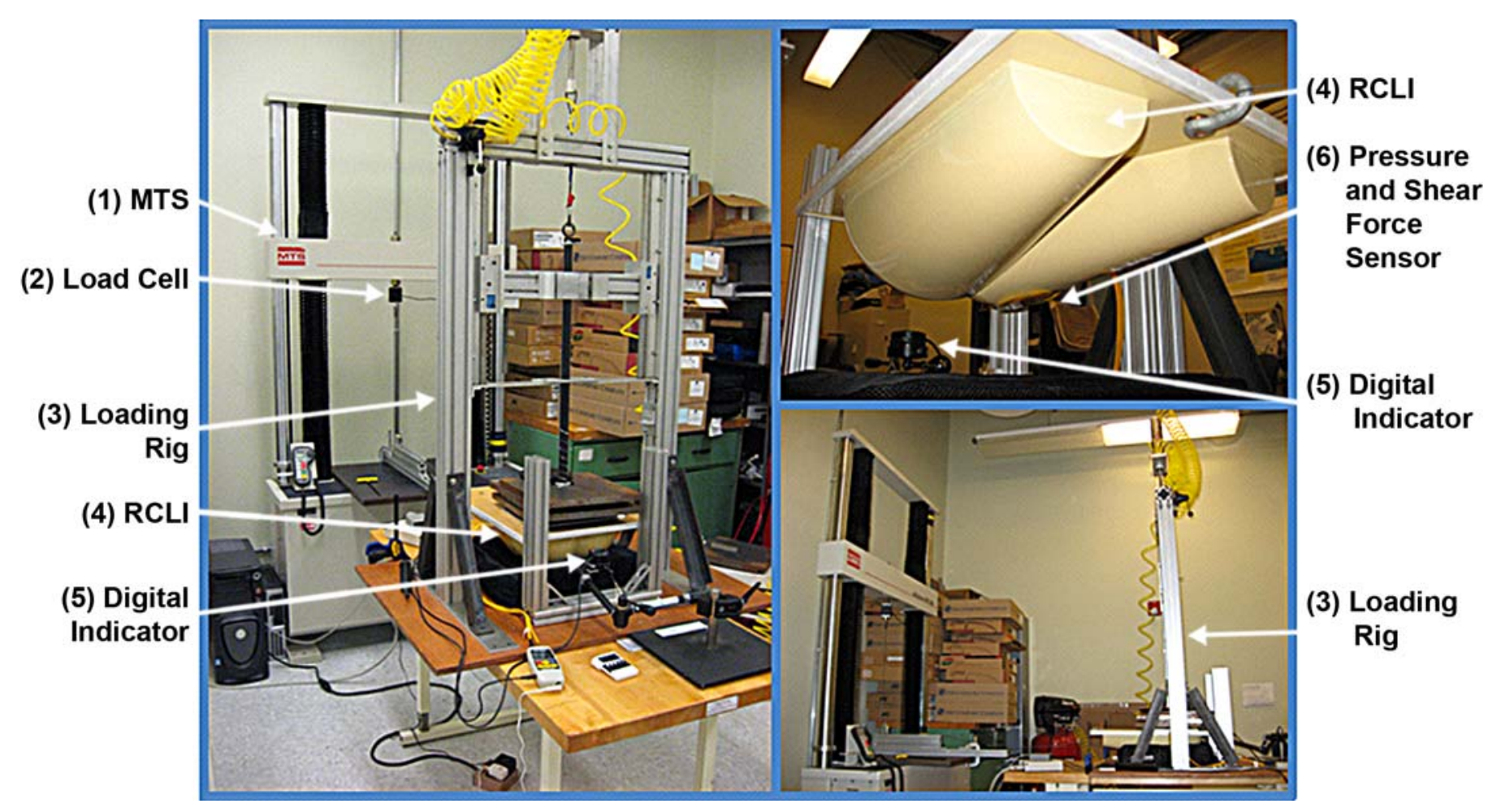

Figure 1.

Test apparatus to obtain shear and pressure characteristics of wheelchair seat cushions. Apparatus consisted of (1) Material Test System (MTS), (2) load cell, (3) loading rig, (4) rigid cushion loading indenter (RCLI), (5) digital indicator, and (6) pressure and shear force sensor. 
JRRD, Volume 48, Number 3, 2011
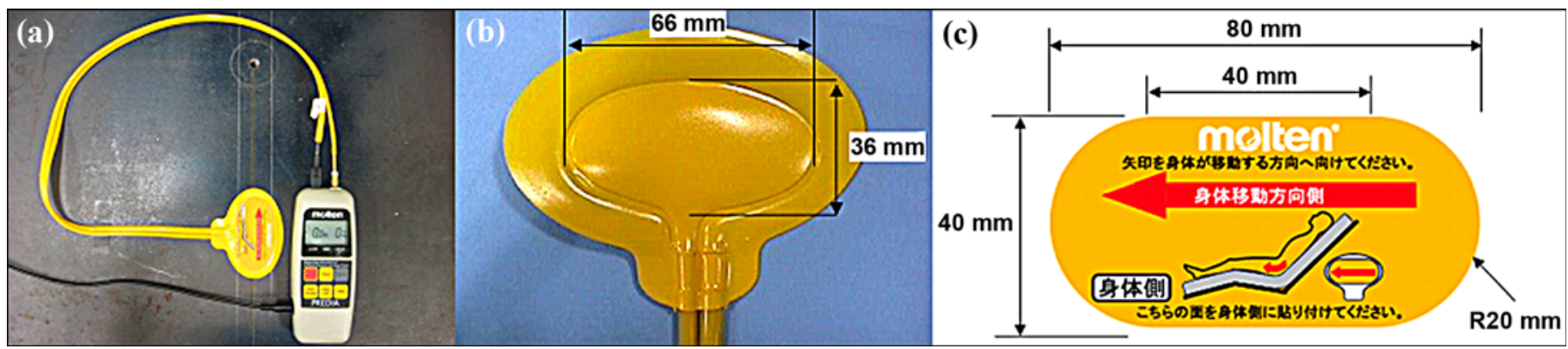

Figure 2.

Predia (Molton Corp; Hiroshima, Japan) pressure and shear force sensor shown (a) assembled and with (b) dimensions for pressure sensing area and (c) dimensions for shear sensing area.

\section{Sensor Validation}

Accuracy of pressure and shear measurements from the sensor was quantified in terms of bias and precision [16]. Measurement bias was assessed by determining the average difference between the measured pressure and shear values and the accepted reference values. Precision was assessed by determining the standard deviation of the difference between the measured pressure and shear values and the accepted refere nce values. Reliability of the sensor was quantified using intrac lass correlation coefficients (ICCs) of pre- and posttesting measurements.

Pressure and shear validity were measured by apply ing known weight and horizont al force, respectively . Pressure was assessed by applying five loads $(8.1,43.0$, $86.0,129.0$, and $172.0 \mathrm{mmHg}$ ) to the sensor that covered the range of the sensor (0-200 $\mathrm{mmHg}$ ). The applied loads were used as the acc epted reference values for pressure. Shear was assessed by applying a pressure of $172 \mathrm{mmHg}$ to the sensor, then applying four displacements $(5,10,15$, and $20 \mathrm{~mm}$ ). The resulting force from the load cell was considered the accepted reference value for shear and was compared with the shear measurement from the sensor. Pressure and shear measurements were recorded $3 \mathrm{sec}$ onds after the pressure/shear was applied. Pre- and posttest measurements were used to calculate ICCs using a two-way random effects model (ICC $[2, \mathrm{k}]$ ).

\section{Protocol}

The protocol chosen for this study was a modified "Lateral and Forward Stiffness" test from "A nnex C" of ISO 16840-2 [14]. ISO 16840-2 specifies that one horizontal displacement $(10 \mathrm{~mm})$ be applied to the RCLI, with the resulting horizontal force recorded after $60 \mathrm{sec}$ onds. Using a modified pro cedure, we applied multiple horizontal displacements $(0,10,15,20 \mathrm{~mm})$ and recorded the resulting horizontal force after 60 seconds. The rationale for additional horizontal displacements was to calculate an actual stiffness variable from the slope of the resulting force-displacement curve. Actual stiffness cannot be calculated with a single force measurement.

The protocol consisted of preconditioning and testing phases. For preconditioning, cushions were acclimated to target test environment of $23 \pm 2{ }^{\circ} \mathrm{C}$ and $50 \pm 5$ percent relative humidity for 12 hours and adjusted to accommodate an $830 \pm 10 \mathrm{~N}(84.7 \pm 1.0 \mathrm{~kg})$ load, if applicable. The preconditioning phase consisted of two load/unload cycles. Each cycle consisted of an $830 \pm 10 \mathrm{~N}(84.7 \pm 1.0 \mathrm{~kg})$ load applied for 150 seconds with the RCLI and a recovery period of 120 seconds. After preconditioning, cushions were allowed a recovery time of a minimum of 5 minutes and a maximum of 60 minutes. Cushions were then adjusted to accommodate a $500 \pm 10 \mathrm{~N}(51.0 \pm 1.0 \mathrm{~kg})$ load and the cushion material reset, if ap plicable. Cushions were positioned under the RCLI such that the ITs of the indenter were $125 \pm 25 \mathrm{~mm}$ forward of the back edge of the cushion or aligned with the cushion feature designed to accommodate the ITs. The testing phase consisted of five trials each of four horizontal RCLI displacements of $0,10,15$, and $20 \mathrm{~mm}$. A vertical load of $500 \pm 10 \mathrm{~N}(51.0 \pm 1.0 \mathrm{~kg})$ was applied to the cushion via the RCLI. Within $60 \pm 5$ seconds, a horizontal RCLI displacement was applied at a rate of $2 \pm 1 \mathrm{~mm} / \mathrm{s}$ and held for 60 seconds. The cushion was unloaded, material was reset, and the cushion was reloaded within 120 seconds.

\section{Data Analysis and Reduction}

Interface pressure, interface shear force, horizontal force, and horizontal RCLI displacements were recorded 
for each RCLI displacement after 60 seconds. Mean horizontal force and interface shear force measurements were used with horizontal RCLI displacements $(0,10,15$, and $20 \mathrm{~mm}$ ) to construct force-displacement and shear-forcedisplacement curves, respectively. A regression analysis of the force-displacement and shear-force-displacement curves resulted in overall ho rizontal stiffness and local horizontal stiffness, respectively. Overall horizontal stiffness was defined as the cushio n's ability to resist a tan gentially applied force, and local horizontal stiffness was defined as the cushion's ability to locally resist a tangentially applied force. Since ma ny cushions are composed of a combination of materials, a local value of stiffness was warranted. ISO 16840-2 stiffness was calculated per the standard as the me an horizontal force measured at $10 \mathrm{~mm}$ horizontal displacement after 60 seconds.

\section{Statistical Analysis}

Kruskal-Wallis tests were performed to determi ne whether interface shear stress and interface pressure increased with applied displacement $(\alpha=0.05)$. Cushions were then categorized into groups based on the materials of construction: viscous fluid $(n=5)$, air cell $(n=7)$, elastic/viscoelastic (VE) foam $(n=6)$, and honeycomb $(n=3)$. K ruskal-Wallis tests were performed to determine whether material of construction significantly changed interface shear stress, interface pressure, or horizontal stiffness measurements $(\alpha=0.05)$. Nonparametric tests were chosen because of violations of equal variance.

To determine whether rela tionships existed between interface shear stress and horizontal stiffness of cushions, we calculated Pearson product moment correlation coefficients $(\alpha=0.05)$. Specifically, correlation coefficients were calculated between mean interface shear stress and overall horizontal stiffness, mean horizontal force and local horizontal stiffness, overall horizontal stiffness and ISO 16840-2 stiffness, and local horizontal stiffness and ISO 16840-2 stiffness. All statistics were analyzed with SPSS statistical software (SPSS, Inc; Chicago, Illinois).

\section{RESULTS}

\section{Sensor Validation}

Measurement bias and precision were calculated for pre- and posttest data (Table 2). Due to the large measurement bias for pressure, a calibration curve was constructed. The calibration curve was a plot of the measured pressure versus the ac cepted reference value, and a second order polynomial regression line was fitted. The regression equation was used to calculate corrected pressure data. Pressure resulted in excellent reliability $(\mathrm{ICC}=0.993)$, and shear resulted in good reliability $(\mathrm{ICC}=0.885)$.

\section{Interface Shear Stress}

Two elastic foam cushions were exclude d from all analyses because shear sensor saturation $(50 \mathrm{~N})$ occurred. Interface shear stress rang ed from 0.8 to $14.9 \mathrm{kPa}$, increased significantly with applied displacement $(p<$ 0.001) (Figure 3(a)), and differed significantly by material of construction for al 1 displacements $(p<0.03)$. Mann-Whitney $U$-tests were performed to determine the location of the significant differences using a Bonferroni correction $(\alpha=0.05 / 4=0.013)$. At $0-\mathrm{mm}$ displacement, only viscous fluid and elastic/VE foam were significantly different $(p=0.001)$. Interface shear stress was signifi cantly different for all materials of construction at 10, 15, and $20 \mathrm{~mm}$ displacements $(p<0.006)$, with the exception of air cell and elastic/VE foam for displacements of 10 $(p=0.08)$ and $15 \mathrm{~mm}(p=0.03)$.

\section{Interface Pressure}

Interface pressure ranged from 8 to $78 \mathrm{mmHg}$, did not increase significantly with applied displacement $(p=$ 0.09 ), and differed significantly by material of constru ction for all displacements $(p<0.001)$ (Figure 3(b)). Mann-Whitney $U$-tests $(\alpha=0.013)$ resulted in significantly different interface pressure for all materials of construction $(p<0.001)$, except viscous fluid and elastic/ $\mathrm{VE}$ foam for all displacements $(p=0.18-0.42)$.

Table 2.

Measurement bias and precision of pressure and shear force sensor (data presented as mean \pm standard deviation).

\begin{tabular}{|c|c|c|c|c|c|c|}
\hline \multirow{2}{*}{ Measurement } & \multicolumn{3}{|c|}{ Measurement Bias } & \multicolumn{3}{|c|}{ Measurement Precision } \\
\hline & Pre & Post & Average & Pre & Post & Average \\
\hline Pressure (mmHg) & $20.46 \pm 23.10$ & $20.00 \pm 27.60$ & - & $3.25 \pm 2.60$ & $2.50 \pm 1.20$ & - \\
\hline Shear $(\mathrm{kPa})$ & $-2.60 \pm 5.11$ & $0.64 \pm 2.73$ & $-0.98 \pm 3.92$ & $0.83 \pm 0.36$ & $0.37 \pm 0.26$ & $0.60 \pm 0.31$ \\
\hline
\end{tabular}




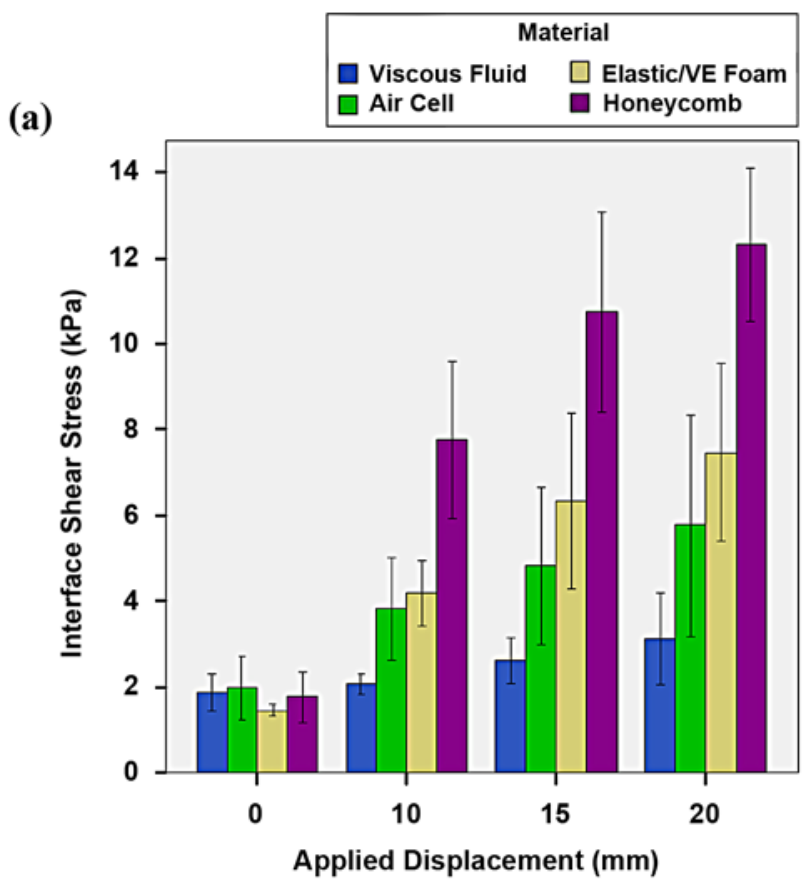

(b)

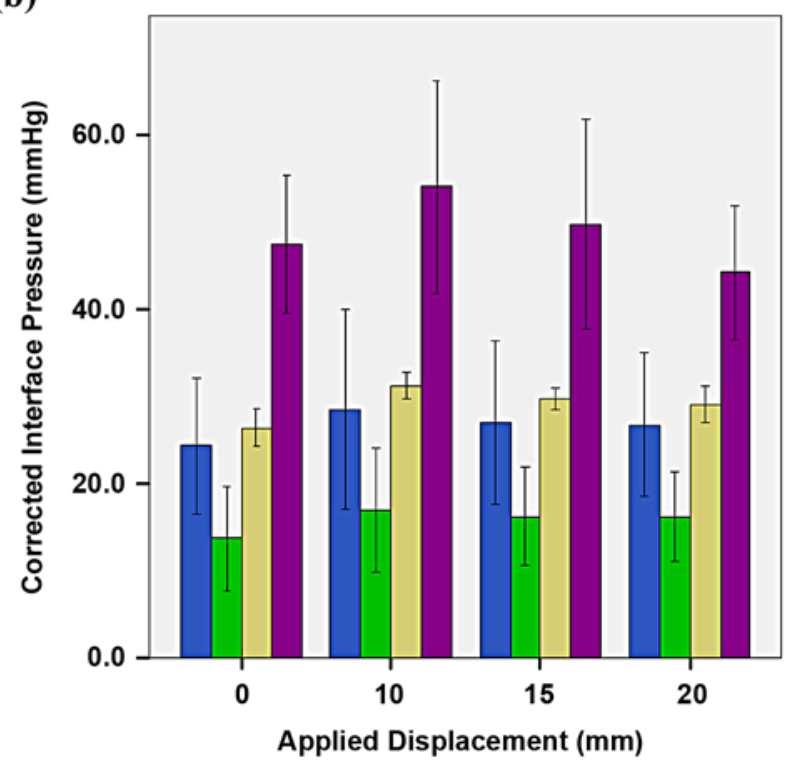

Figure 3.

Results of (a) interface shear stress and (b) interface pressure across applied displacement $(0,10,15,20 \mathrm{~mm})$ by material of construction: viscous fluid $(n=5)$, air cell $(n=7)$, elastic/VE foam $(n=4)$, and honeycomb $(n=3)$. Interface shear stress increased significantly across applied displacement $(p \leq 0.001)$ and interface pressure did not $(p=0.09) . \mathrm{VE}=$ viscoelastic .

\section{Horizontal Stiffness}

Overall horizontal stiffness and ISO 16840-2 stiffness were not significantly dif ferent between material of con- struction ( $p=0.29$ and $p=0.14$, respectively) and their results were similar (Figure 4). Local horizontal stiffness was significantly different for material of construction ( $p=0.007)$, and Mann-Whitney $U$-tests were performed to determine the location of the significant difference $(\alpha=$ 0.013). While the Bonferroni corrected alpha level failed to find a significant difference $(p>0.013)$, viscous fluid and elastic/VE foam $(p=0.014)$ and air cell and honey comb $(p=0.017)$ were nearly significantly different.

Significant positive relationships were found between local horizontal stiffness and horizontal forc e $(r=0.49$ and $r=0.51$, respectively); however, no significant correlations were found between interface shear stress and overall horizontal stiffness $(0.09<r<0.35)$ as shown in Table 3. A positive correlation was found between overall horizontal stiffness and local horizontal stiffness, and significant positive correl ations were found between overall and local stiffness values and ISO 16840-2 stif fness ( $r=0.95$ and $r=0.51$, respectively), as shown in Table 4.

\section{DISCUSSION}

Pressure and shear are the mechanical extrinsic risk factors known to increase the risk of pressure ulcers [5]. Pressure mapping has allowed quantification of interface pressure and a visual representation of real-time pressure redistribution. Clinicians have incorporated the pressure mapping tool to aid in the decision-making process of cushion prescriptions. This was the first study to quantify interface shear stress of commercial wheelchair seat cushions and provides clinic ians additional information about a cushion's response to horizontal displacement.

\section{Sensor Validation}

The pressure and shear force sensor used in this study was used in previous studies [17-21], and the shear force measurement error was established as $\pm 1 \mathrm{~N}$ by Nakagami et al., Okazaki et al., an d Okubo et al. [17,2 0-21] and $2.7 \mathrm{~N}$ by Oduncu and Melhuish [18]. Measurement bias of shear force was $-2.8 \mathrm{~N}(-0.98 \mathrm{kPa})$, and precision was $1.7 \mathrm{~N}$ $(0.60 \mathrm{kPa})$. The greater error observed in this study may be due to a larger range of measured shear force. The largest range of shear force in prev ious studies was from 0 to $11.7 \mathrm{~N}$ [17] compared with 0 to $41.9 \mathrm{~N}(0.8-14.9 \mathrm{kPa})$ in this study. In the previous studies, the sensor was adhered to a flat, rigid surface and different wound dressings were 
AKINS et al. Shear and pressure characteristics of wheelchair seat cushions

(a)

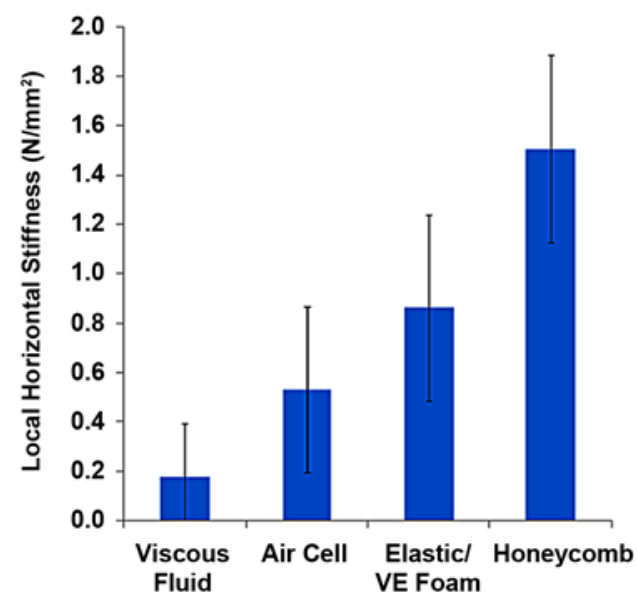

(b)

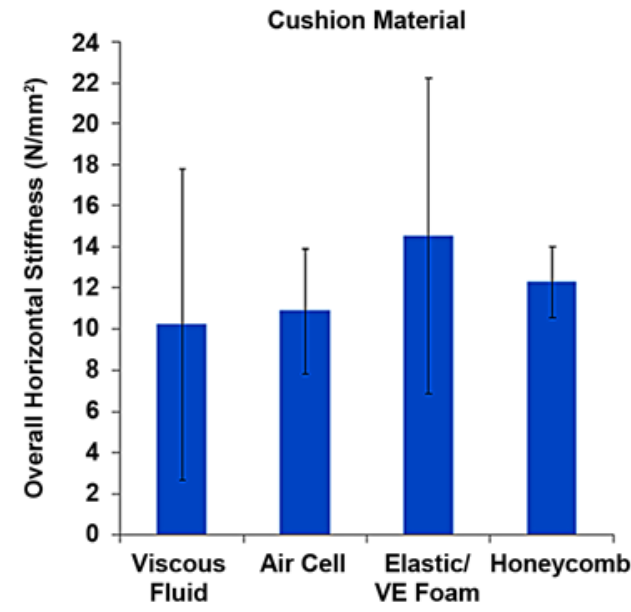

(c)

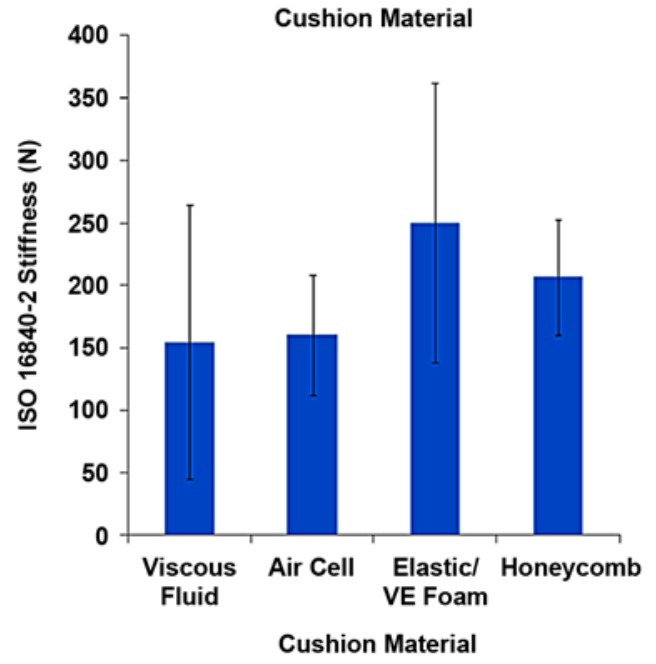

Figure 4.

Horizontal stiffness by material of construction: viscous fluid $(n=5)$, air cell $(n=7)$, elastic/VE foam $(n=4)$, and honeyco $\mathrm{mb}(n=3)$. (a) Local horizontal stiffness was significantly different by material of construction $(p=0.007)$ and no significant difference was found for (b) overall horizontal stiffness $(p=0.29)$ o $\mathrm{r}$ (c) International Organization for Standardization (ISO) $16840-2$ stiffness $(p=0.14) . \mathrm{VE}=$ viscoelastic.
Table 3.

Correlation coefficients $(r)$ for forces and horizontal stiffness values.

\begin{tabular}{cccc}
\hline Force & $\begin{array}{c}\text { RCLI } \\
\text { Displacement } \\
(\mathbf{m m})\end{array}$ & $\begin{array}{c}\text { Overall } \\
\text { Horizontal } \\
\text { Stiffness }\end{array}$ & $\begin{array}{c}\text { Local } \\
\text { Horizontal } \\
\text { Stiffness }\end{array}$ \\
\hline Interface & 10 & 0.09 & - \\
Shear Stress & 15 & 0.33 & - \\
& 20 & 0.35 & - \\
Horizontal & 10 & - & $0.51^{*}$ \\
Force & 15 & - & $0.49^{*}$ \\
& 20 & - & 0.43 \\
\hline
\end{tabular}

${ }^{*}$ Correlation significant at 0.05 level.

$\mathrm{RCLI}=$ rigid cushion loading indenter.

Table 4.

Correlation coefficients $(r)$ for horizontal stiffness values.

\begin{tabular}{lccc}
\hline \multicolumn{1}{c}{ Stiffness } & $\begin{array}{c}\text { Overall } \\
\text { Horizontal } \\
\text { Stiffness }\end{array}$ & $\begin{array}{c}\text { Local } \\
\text { Horizontal } \\
\text { Stiffness }\end{array}$ & $\begin{array}{c}\text { ISO 16840-2 } \\
\text { Stiffness }\end{array}$ \\
\hline Overall Horizontal Stiffness & 1 & 0.43 & $0.95^{*}$ \\
Local Horizontal Stiffness & - & 1 & $0.51^{\dagger}$ \\
ISO 16840-2 Stiffness & - & - & 1 \\
${ }^{*}$ Correlation significant at 0.01 level. & & \\
${ }^{\dagger}$ Correlation significant at 0.05 level. & & \\
ISO = International Organization for Standardization. \\
\hline \hline
\end{tabular}

evaluated by applying a horizontal displacement across the static sensor [17,19]. In this study, the sensor was also adhered to a flat, rigid surface, but the surface and senso $r$ were moved with respect to a static cushion, potentially causing greater error. Establishing bias and precision of the Predia pressure an $d$ shear force sensor will allow future researchers to use the sensor with confidence.

\section{Interface Shear Stress and Pressure}

Bennett et al. and Goossens et al. previously measured interface shear stress of rigid plastic $(0.9-2.6 \mathrm{kPa})$ [11-12], wood (4.6-9.6 kPa) [ 22], foam (6.5-6.8 kPa) [23], gel (4.4-6.4 kPa) [22-23], and a LiquiCell (LiquiCell Technologies, Inc; Eden Prairie, Minnesota) overlay $(4.0-4.8 \mathrm{kPa})$ [23]. In this study, interface shear stress ranged from 0.8 to $14.9 \mathrm{kPa}$. The greater amount of interface shear stress measured in this study was most likely due to a different sensor and the RCLI. The difficulty in obtaining interface shear stress measurements has simply been the lack of sensors capable of such measurements. Bennett et al. noted that the sensor used in the ir study would register less than the true value of loca 1 shear because dissimilar ma terials were in contact with the 
sensor and the sensor was located 2 to $3 \mathrm{~cm}$ lateral of the IT [10]. The sensor used by Goossens et al. was not completely validated [22], whic $\mathrm{h}$ could be a reason for the greater values in this study. Measurements obtained by all sensors were on the same order of magnitude, and the primary advantage of the sensor used in this study is that it is commercially available. The RCLI is made of fiberglass and would likely create larger interface shear stresses than soft tissues because fiberglass is not compliant.

Interface pressure of cushions has been evaluated previously on foam, air, gel, and powered alternating cushions [6-7]. Mean interface pressures ranged from 6.13 to 20.93 $\mathrm{kPa}(46-157 \mathrm{mmHg})$, and peak interface pressures satu rated the sensor at $26.66 \mathrm{kPa}(200 \mathrm{mmHg})$. In this study, mean interface pressure ranged from 1.07 to $10.40 \mathrm{kPa}(8-$ $78 \mathrm{mmHg}$ ). The discrepancy between the previous studies and this study is most likely due to the meth od of force application and sensor placement. Forces were appl ied to cushions using humans in the prev ious studies, and an RCLI was used in this study. Variations between humans and the RCLI include rigidity, size, and shape. The sensor was placed just anterior to the left IT of the RCLI and provided a flat, rigid surface. Placing the sensor d irectly on the IT resulted in bending of the sensor, and pilot data indicated that this bending resulte $d$ in erroneous pressure and shear force measurements. Therefore, the sensor was moved just anterior to the IT because the surface was flat.

Interface shear stress was significantly different for all materials of construction, except air cell and elastic/VE foam at 10 and $15 \mathrm{~mm}$, and increased significantly with increased displacement. Interface shear stress is a measure of a cushion' $s$ ability to ab sorb applied displacements without transferring shearing force to soft tissues. Viscous fluid resulted in the least amou nt of interface shear stress followed by air cell, elastic/VE foam, and honeycomb. These differences were more evident at higher displacements. Animal studies have demonstrated that shearing forces increase severity of pressure ulcers and decrease cutaneous blood flow [8-9]. Future research should focus on establishing a threshold for an acceptable level of interface shear stress at bony prominences. Interface pressure varied significantly for all materials of construction, except viscous fluid and elastic/VE foam, and did not increase with increased displacement. Air cell cushions had the lowest interface pr essure followed by viscous fluid, elastic/VE foam, and honeycomb. Lower interface pressure is associated with reduced risk of pressure ulcer development [6].

\section{Horizontal Stiffness}

In a previous study, horizontal stiffness was collected for 21 wheelchair seat cushions using the "Lateral and Forward Stiffness" test protocol from "Annex C" of ISO 16840-2 [24]. The same protocol was used to determine horizontal stiffness as in this study except that only on e displacement $(10 \mathrm{~mm})$ was u sed. The horizontal stiffness measurements ranged from 80 to $325 \mathrm{~N}$ compared with 92 to $403 \mathrm{~N}$ in this study (recorded at $10 \mathrm{~mm}$ displace ment). The reason for greater values measured in this study was likely the method of securing the cushion during testing. In the previous study, the cushion was adhered to a scale [24] compared with a rigid base in this study. The scale was designed with flexible plastic tabs at each corner to stabilize a platform and possibly absorbed a portion of the horizontal force, resulting in lower measurements.

Our rationale for using the horizontal stiffness measurement was that it relates to the amount of she ar stress imparted by the cushion to the patient's soft tissue. The higher the horizontal stiffness, the higher the shear stress. Overall horizontal stiffness and ISO 16840-2 stiffness resulted in similar results wh en grouped by material of construction, and neither measure differentiated cushions by material of construction. Elastic/VE foam had the largest stiffnesses and viscous fluid, air cell, and honeycomb were similar $(p>0.14)$. In contrast, local horizontal stiffness was significantly dif ferent by material of construction $(p=0.007)$. The trend in lo cal horizontal stiffness values was the same as for interface shear stress; viscous fluid resulted in the least amount of local hori zontal stiffness followed by air cell, elastic/VE foam, and honeycomb. Additionally, no significant relationship was noted between interface shear stress and overall horizontal stiffness $(0.08<r<0.35)$. These results indicate that testing the overall horizontal stiffness of a cushion does not provide information abou t the cushion's ability to reduce interface shear stress at the IT.

The high correlation between ISO 16840-2 stiffness and overall horizontal stiffness $(r=0.95)$ shows that the current horizontal stiffness test methodology ("Annex C" of ISO 16 840-2) provides sufficient information about overall horizontal cushion stiffness. The single displacement used to $c$ alculate ISO 16840-2 stif fness requires less testing, data processing, and data analysis. Due to the lack of a relationship between interface shear stress and overall horizontal stif fness, a pressure and shear force sensor should be used with ISO 16840-2 stiffness to fully quantify a cushion's ability to reduce interface shear at the patient's bony prominences. 
AKINS et al. Shear and pressure characteristics of wheelchair seat cushions

\section{Limitations}

Limitations exist in our ability to compare values in this study with those from previous studies because of the use of different shear sensors and potential erroneous forces created by the sensor itself. Shear sensors used in previous studies were not available for thi s study and are not commercially available. Placement of the sensor in between the RCLI and the cushion surface changes th e actual cont act conditions and may introduce forces that are not normally present; however, this limi tation will be inherent with any sensor . Another limitation of thi s study was the inability to control relative humidity during testing. ISO 16840-2 required a relative humidity of $50 \pm 5$ per cent, and we were unable to maintain this range during testing. Fluctuations in relative humidity may result in different shear force measurements because of changes in the coefficient of friction. Future studies should investigate the variation in the coefficient of friction due to changes in relative humidity and microclimate.

\section{CONCLUSIONS}

This study qu antified interface shear stress, in terface pressure, and horizontal stiffness for commercial wheelchair seat cushions and determined whether a relationship existed between interface shear stress and horizontal stiffness of cushions. Cush ions were grouped by material of construction, and we fo und that interface sh ear stress increased significantly with increased displacement. Viscous fluid cushions resulted in the least amount of interface shear stress followed by air cell, elastic/VE foam, and honeycomb. These differences were more evident at higher displacements. No significant differences in interface pressure were found with increased displacement. The high correlation between ISO 16840-2 stiffness and overall horizontal stiffness indicates that the curr ent horizontal stiffness test methodology ("Annex C" of ISO 1684 0-2) provides sufficient information about overall horizontal cushion stiffness. However, these measures do not provide information about the cushion's ability to reduce in terface shear stress at the patient's IT, and an interface shear stress sensor may aid clinicians in their cushion selection.

\section{ACKNOWLEDGMENTS}

\author{
Author Contributions: \\ Study concept and design: J. S. Akins, D. M. Brienza, P. E. Karg. \\ Acquisition of data: J. S. Akins.
}

Analysis and interpretation of data: J. S. Akins, D. M. Brienza, P. E. Karg.

Drafting of manuscript: J. S. Akins.

Critical revision of manuscript for important intellectual content: J. S. Akins, D. M. Brienza, P. E. Karg.

Statistical analysis: J. S. Akins.

Obtained funding: J. S. Akins, D. M. Brienza.

Administrative, technical, or material support: J. S. Akins, D. M. Brienza, P. E. Karg.

Study supervision: D. M. Brienza.

Financial Disclosures: The authors have declared that no competing interests exist.

Funding/Support: This material was based on work supported by the National Institute on Disability and Rehabilitation Research (NIDRR), Rehabilitation Engineering Research Center on Spinal Cord Injury (grant H133E070024). This work was also funded in part under The Technology Collaborative (TTC); (Pittsburgh, Pennsylvania; grant 705244).

Additional Contributions: We are grateful to The Comfort Company; The ROHO Group, Inc; Sunrise Medical, Inc; and Supracor, Inc, for providing the cushions for this study; and Mr. Eric Porach for his assistance with data collection.

Disclaimer: The ideas and opinions expressed herein are those of the authors and not necessarily reflective of the NIDRR and TTC. Since the completion of the study, Mr. Akins has received his Master of Science in Bioengineering.

\section{REFERENCES}

1. Miller H, Del ozier J. Co st implications of the p ressure ulcer treatment guideline. Columbia (MD): Center for Health Policy Studies, Agency for Health Care Policy and Research; 1994. Contract No. 282-91-0070.

2. Russo CA, Elixhauser A. Hospi talization related to pressure sores, 2003. Healthcare Cost and Utilization Project (HCUP) Statistical Brief \#3. Rockville (MD): Agency for Healthcare Research and Quality; 2006 [cited 2007 Jan 26]; Available from: http://www.hcup-us.ahrq.gov/reports/ statbriefs/sb3.pdf.

3. Whittington KT, Briones R. National Prevalence and Incidence Study: 6-year sequential acute care data. Adv Skin Wound Care. 2004;17(9):490-94. [PMID: 15632743] DOI:10.1097/00129334-200411000-00016

4. Fitzgerald SG, Thorman T, Cooper R, Cooper RA. Evaluating wheelchair cushions. Rehab Management. 2001 Feb.

5. Brienza DM, Geyer MJ. Using support surfaces to manage tissue integrity. Adv Skin Wound Care. 2005;18(3):151-57. [PMID: 15840984]

DOI:10.1097/00129334-200504000-00013

6. Brienza DM, Karg PE, Geyer MJ, Kelsey S, Trefler E. The relationship between pressure ulcer incidence and buttockseat cushion interface pressure in at-risk elderly wheelchair users. Arch Phys Med Rehabil. 2001;82(4):529-33. 
[PMID: 11295017]

DOI:10.1053/apmr.2001.21854

7. Burns SP, Betz KL. Seating pressures with conventional and dynamic wheelchair cushions in tetraplegia. Arch Phys Med Rehabil. 1999;80(5):566-71. [PMID: 10326923] DOI:10.1016/S0003-9993(99)90201-0

8. Dinsdale SM. Decubitus ulcers: Role of pressure and friction in cau sation. Arch Phys Med Rehabil. 1974;55(4): 147-52. [PMID: 4595834]

9. Goldstein B, Sanders J. Skin response to repetitive mechanical stress: A new experimental model in pig. Arch Phys Med Rehabil. 1998;79(3):265-72. [PMID: 9523777] DOI:10.1016/S0003-9993(98)90005-3

10. Bennett L, Kavner D, Lee BK, Trainor FA. Shear vs pressure as causative factors in skin blood flow occlusion. Arch Phys Med Rehabil. 1979;60(7):309-14. [PMID: 454129]

11. Bennett L, Kavner D, Lee BY, Trainor FS, Lewis JM. Skin blood flow in seated geriatric patients. Arch Phys Med Rehabil. 1981;62(8):392-98. [PMID: 7259473]

12. Bennett L, Kavner D, Lee BY, Trainor FS, Lewis JM. Skin stress and blood flow in sitting paraplegic patients. Arch Phys Med Rehabil. 1984;65(4):186-90. [PMID: 6712437]

13. Goossens RH, Zegers R, Hoek van Dijke GA, Snijders CJ. Influence of shear on skin oxygen tension. Clin Physiol. 1994;14(1):111-18. [PMID: 8149705] DOI:10.1111/j.1475-097X.1994.tb00495.X

14. International Organization for Standardization (ISO). Wheelchair seating - Part 2: Determination of physical and mechanical characteristics of devices intended to manage tissue integrity—Seat cushions. 2007. Geneva, Switzerland. ISO 16840-2.

15. Medicare wheelchair cushion HCPCS co ding eligibility requirement for ROHO products [Internet]. Belleville (IL): The ROHO Group; 2008 [cited 2008 Jun 13]. Available from: http://trgweb.rohoinc.com/Web\%20Databases/PDFs/ Web\%20PDFs.nsf/0/ C2B64D77F9B27C09862571A7004ACA2C/\$File/Medicare+Seating+Algorithm +5 10.pdf.

16. ASTM. Standard practice for use of the terms precision and bias in ASTM test met hods. West Conshohocken (PA): ASTM; 1996.

17. Nakagami G, Sanada H, Kony a C, Kitagawa A, Tadaka E, Tabata K. Comparison of two pressure ulcer preventive dress- ings for reducing shear force on the heel. J Wound Ostomy Continence Nurs. 2006;33(3):267-72. [PMID: 16717516]

18. Oduncu H, Melhuish J. Evaluation of sensors for measuring shear forces associated with wound healing and formation. Poster presented at: Wounds UK 2007 Wound Care Conference Harrogate; 2007; Harrogate, United Kingdom.

19. Ohura T, Takahashi M, Ohura N Jr. Influence of external forces (pressure and shear for ce) on superficial layer and subcutis of porcine skin and effects of dressing materials: Are dressing materials beneficial for reducing pressure and shear force in tissues? Wound Repair Regen. 2008;16(1): 102-7. [PMID: 18086290]

20. Okazaki H, Mimura M, Takano K, Shiokawa M, Ohura T, Takahashi M. [The development and validity of a sensor for simultaneously measuring pressure and shear force]. Jpn J Pressure Ulcers. 2002;4:263. Japanese.

21. Okubo Y, Konagaya M, Ogawa K. [The sliding effects on the supinated human body due to bed inclination]. Jpn J Pressure Ulcers. 2000;2(1):45-50. Japanese.

22. Goossens RH, Snijders CJ, Holscher TG, Heerens WC, Holman AE. Shear stress measured on beds and wheelchairs. Scand J Rehabil Med. 1997;29(3):131-36. [PMID: 9271146]

23. Goossens RH. Shear stress measured on three dif ferent cushioning materials. Eden Prairie (MN): LiquiCell Technologies, Inc.; 2001.

24. Bafana R. Development, evaluation and implementation of wheelchair seat cushion testing standards, [master's thesis]. [Pittsburgh (PA)]: University of Pittsburgh; 2005.

Submitted for publication September 6, 2009. Accepted in revised form October 18, 2010.

This article and any supplementary material should be cited as follows:

Akins JS, Karg PE, Brienza DM. Interface shear and pressure characteristics of wheelchair seat cushions. J Rehabil Res Dev. 2011;48(3):225-34. DOI:10.1682/JRRD.2009.09.0145

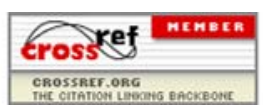

